\title{
Experimental and numerical study on the design of a deposition basin outlet structure at a mountain debris cone
}

\author{
B. Gems ${ }^{1}$, M. Wörndl ${ }^{1}$, R. Gabl ${ }^{1}$, C. Weber ${ }^{2}$, and M. Aufleger ${ }^{1}$ \\ ${ }^{1}$ Unit of Hydraulic Engineering, University of Innsbruck, Innsbruck, Austria \\ ${ }^{2}$ Austrian Service for Torrent and Avalanche Control, Imst regional headquarters, Austria \\ Correspondence to: B. Gems (bernhard.gems@uibk.ac.at) \\ Received: 16 May 2013 - Published in Nat. Hazards Earth Syst. Sci. Discuss.: 8 July 2013 \\ Revised: 22 November 2013 - Accepted: 3 December 2013 - Published: 4 February 2014
}

\begin{abstract}
Mountain debris cones in the Alpine region often provide space for dense population and cultivation. Hence, a great number of buildings are exposed to torrential hazards. In order to protect the settlement areas against flooding and overbank sedimentation, torrent defence structures are implemented at various locations within catchments. Directly at the debris cones, these protection measures often include a deposition basin at the fan apex and/or a confined channel that passes through the settlement.

The work presented within this paper deals with the effect of specific outlet structure layouts, situated at the lower end of a selected deposition basin, on bed-load transport processes and flood protection. A case study analysis was accomplished comprising a 3-D numerical model (FLOW-3D) and a physical scale model test $(1: 30)$. The subject of investigation was the deposition basin of the Larsennbach torrent in the Austrian Northern Limestone Alps. The basin is situated on a large debris cone and opens out into a paved channel. Since the basin is undersized and the accumulation of sediment in the outlet section reduces the available cross section during floods, adjoining settlements are considerably endangered of lateral overtopping of both clear water and sediment. Aiming for an upgrade in flood protection, certain layouts for a "closing-off structure" at the outlet were tested within this project. For the most efficient design layout, its effect on flood protection, a continuous bed-load output from the basin and the best possible use of the retention volume are pointed out. The simple design of the structure and the key aspects that have to be taken into consideration for implementation are highlighted.
\end{abstract}

\section{Introduction}

Settlement development in Alpine valleys is marked by a lack of habitable space. Housing areas, infrastructure facilities and industrial areas are, in a number of instances, exposed to torrential hazards. Sufficient protection requires both measures for the analysis and reduction of the damage and hazard potential (Fuchs et al., 2007; Gems, 2011; Holub et al., 2012; Huttenlau et al., 2010; Mazzorana et al., 2012). The latter comprises active and passive measures (Bergmeister et al., 2009; Lange and Bezzola, 2006; Zollinger, 1983); torrent defence works to prevent flooding and overbank sedimentation in adjoining settlements, in particular. Sediment transport processes significantly influence the process nature of floods in torrent catchments and accordingly the level of danger (Gems, 2011). Depending on the catchment characteristics and on the process pattern of torrential hazards, events featuring exclusively flooded water bodies due to debris flows, yielding average sediment concentrations of up to $70 \%$ of the solid-liquid mixture, occur (Aulitzky, 1984; Bergmeister et al., 2009; DIN 19663, 1985; Hübl, 2009; ONR 24800, 2009). Typically, both the hazard potential and the potential losses increase with an increasing sediment ratio. The history of torrential events in the Alpine region entirely confirms and emphasizes this statement (Bezzola et al., 2007; Rudolf-Miklau et al., 2006, 2012).

When analysing the spatial characteristics of the Alpine region's settlement areas, densely populated areas are frequently found at mountain debris cones. This is partly a result of the limited availability of habitable space. It is also caused by former hydroagricultural land development and by the hazard potential of the large, and in the past for the most 
part untouched valley rivers (Bätzing, 1991). In many cases the present day situation at the debris cones requires not only torrent control works in the upper catchment parts, but also protection measures at the debris cones within the settlement areas. These measures often comprise a deposition basin, which is situated at the fan apex and aims for the retention of a significant proportion of the incoming bed load. The basin often leads into a paved channel, which passes through the settlement area and finally enters the receiving water course. To ensure a well-functioning flood protection and bed-load management system at the debris cone, the deposition of sediment in the basin has to be large enough to prevent lateral overtopping in the settlements. It may also enable a continuous onward transport of a certain amount of sediment so as not to cause a deficit in the receiving water course. The design of the paved channel and the junction to the receiving water course must not encourage regressive accumulation along the channel due to a backwater effect caused by the receiving water course. Both the design of the deposition basin and the constructional requirements of the paved channel, including the junction into the receiving water course, represent topics for currently ongoing and future challenging research (Hübl et al., 2002, 2012; Hunzinger and Zarn, 1996; Kaitna et al., 2011; Kerschbaumer, 2008).

The work presented within this paper deals with the design of a deposition basin's outlet structure. The analysis was done for a basin situated at the debris cone of the Larsennbach torrent catchment. It was accomplished by the use of both a numerical and a physical scale model. Within the analysis, the focus was primarily put on the decrease of accumulation in the transition zone between the basin and the paved channel, as well as on the prevention of lateral overtopping at the basin and along the downstream channel section.

\section{Subject of investigation}

\subsection{Catchment characteristics}

The Larsennbach torrent is situated to the north of the Inn River in the Tyrolean Northern Limestone Alps (Fig. 1a). The catchment covers an area of $20.2 \mathrm{~km}^{2}$, ranging from the entry to the Inn River at $727 \mathrm{~m}$ a.s.l. up to $2827 \mathrm{~m}$ a.s.l. It is entirely unglaciated and sparsely covered with forest vegetation. The catchment's trunk torrent results from the confluence of three main feeder channels in the upper catchment part. Both the feeder/tributary channels and the trunk torrent are supplied with sediment from gully erosion and yielding talus slopes in the upper and middle catchment part. Further downstream, along a distance of $3.5 \mathrm{~km}$, the torrent flows through a canyon, featuring channel widths from 4 to $40 \mathrm{~m}$ and gradients between 6 and $13 \%$, before spreading on a large, densely populated debris cone.

Due to the characteristics of the sedimentary rock (principal dolomite rock with lithographical limestone and marl lay-

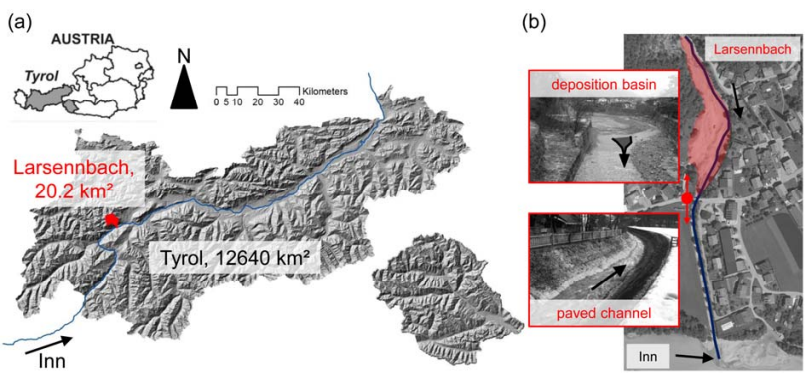

Fig. 1. (a) Location of the Larsennbach torrent catchment in Northern Tyrol; (b) situation at the torrent's debris cone-deposition basin and paved channel in the surroundings of populated area.

ers) and the sparse forest vegetation in the catchment, large amounts of weathered products reach the trunk torrent. They are deposited in flat channel sections where they represent a large portion of the sediment, which is potentially available for remobilization. The hazard potential of the Larsennbach torrent is mainly related to long-lasting, advective precipitation events with medium and high intensities, causing continuous sediment discharges featuring a fluviatile, rather than debris, flow regime (WLV, 2011). Regarding the transport capacities upstream of the deposition basin on the fan apex, high transport rates or rather supply limited conditions are dominating in the canyon reach, whereas even further upstream in the catchment the bed-load transport conditions are more likely to be transport limited. Material, which is activated during floods, further transported along the trunk torrent and partially deposited on the debris cone, is smallgrained and shows a comparatively uniform grain size distribution. These characteristics are specific features of torrent catchments in the Austrian Limestone Alps and significantly differ from crystalline Central Alps conditions and debrisflood/flow torrents, respectively (Hübl et al., 2003; Luzian et al., 2002; Rudolf-Miklau et al., 2006; Sommer and Lauffer, 1982).

According to the Austrian Service for Torrent and Avalanche Control (WLV, 2011) the $150 \mathrm{yr}$ flood peak $\left(\mathrm{HQ}_{150}\right)$ in the Larsennbach torrent amounts to $55 \mathrm{~m}^{3} \mathrm{~s}^{-1}$. Thereof, approximately $10 \%$ relate to the bed-load component (Fig. 2b). The total expected amount of bed load under design flood conditions is roughly estimated to be $100000 \mathrm{~m}^{3}$ or rather $4950 \mathrm{~m}^{3} \mathrm{~km}^{-2}$.

\subsection{Bed-load management within the framework of flood protection}

Within the span of the past few decades, a number of disastrous flood events have occurred at the Larsennbach torrent. They have caused massive damages to buildings and infrastructure in the settled areas on the debris cone. For the purpose of protection against torrential hazards, and due to the impact of bed-load transport processes on the hazard 
(a)

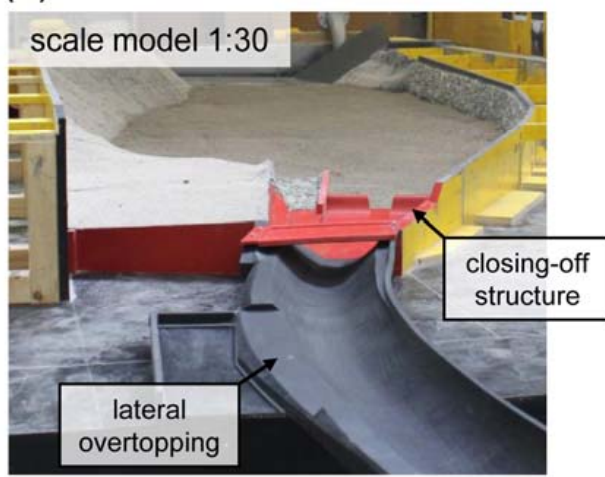

(b)

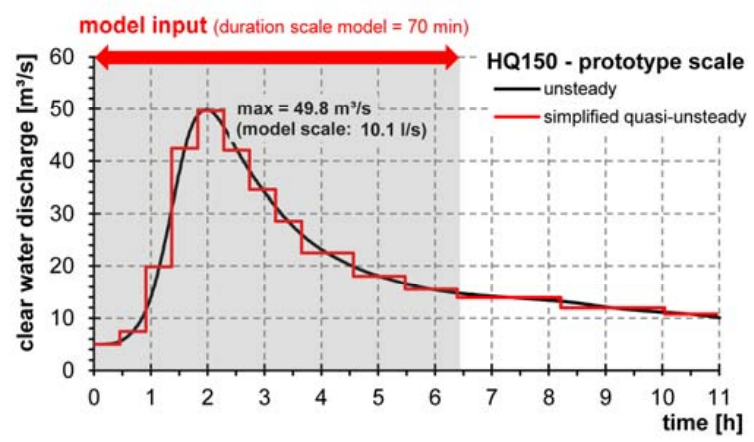

Fig. 2. (a) Overview of the scale model comprising the deposition basin, closing-off structure, bridge, paved channel and the overflow section situated on the orographic right-hand side of the channel; (b) unsteady $\mathrm{HQ}_{150}$-design flood (WLV, unpublished data) and simplified quasi-unsteady hydrograph representing the model input (prototype scale).

potential, a deposition basin is currently situated downstream of the canyon at the fan apex. There are no further mentionable retention or deposition structures in the upper catchment part. The maximum capacity of the basin is $18000 \mathrm{~m}^{3}$. Thus, the basin only allows for the deposition of a certain fraction of the expected bed-load volume. A paved channel featuring a comparatively low gradient of $1.5 \%$ is the outlet of the deposition basin. Subsequently, the channel passes through a bridge structure, leads into a paved channel with a gradient of $3 \%$ and enters into the Inn River (Figs. 1b and 2a).

According to the facts of former flood events, the near range of the bridge structure is, in a sense, the bottleneck for continuous bed-load transport from the basin to the receiving water course: If the amount of material entering the basin considerably exceeds the basin's capacity, intensive bed-load discharge exits the basin and further overloads the channel section at the bridge. There, a bulk of sediment is consequently deposited (WLV, 2011). It partially or entirely blocks the channel and finally causes an overtopping of both clear water and sediment. The flood risk for the populated area is in particular relevant during the falling limbs of flood hydrographs since the bed-load transport capacity decreases, the deposition basin is entirely filled with material and the input from upstream continues due to the boundless supply of small-grained sediment in the catchment.

Due to the torrential hazards under present conditions, the Austrian Service for Torrent and Avalanche Control (WLV, 2011) is currently realizing a set of design measures within the framework of flood protection. Amongst others, the flood walls along the deposition basin and the paved channel are to be heightened, the bridge is reconstructed to enlarge the available cross section and an overflow section is to be set on the right-hand side of the paved channel downstream of the bridge. Further, a "closing-off structure" at the basin's outlet is being designed in order to diminish heavy bed-load deposition upstream of the bridge (WLV, 2011). Together with the other measures, this structure has to comply with the following conditions:

1. Reduction of hazard potential and increased flood protection for the adjoining settlements; the total prevention of overtopping processes under design flood conditions.

2. Maximum possible and regulated output of bed load from the basin so as to avoid an overloading along the channel section at the bridge and the paved channel during the design flood.

3. In the case that overtopping along the paved channel is unpreventable, lateral overflow has to be spatially restricted in a controlled manner at the overflow section.

4. Increase of the deposition basin's maximum capacity; enhanced usage of the basin's capacity by achieving bed-load deposition not only on a certain flow path but throughout the entire width of the basin.

5. The design of the closing-off structure must allow access to excavators in the case of an extreme flood event, to assist in the bed-load transport through the opening; a pondage effect at low flow conditions must not occur.

Clearly, the characterized conditions are explicitly aimed at the reduction of hazard potential and flood risk. Referring to the technical guidelines on torrent and avalanche control (BLFUW, 2006) and to the EU water framework directive (European Parliament, Council, 2000) respectively, a holistic planning process within torrent defence and flood protection management that fully considers also aspects of sediment continuity and ecological compatibility is a mandatory objective. Negative effects on the ecological status of the water body, resulting from specific torrent defence measures, are to 
be avoided within the sense of the prevention of water deterioration. Providing a great public importance of the respective engineering measures and for the case that specific aims are not compatible with each other or the available economic resources are not sufficient to fulfil all requirements, a weighting of interests and a classification of the project aims according to their importance and priority, is required. In respect of these legal requirements, the project at the Larsennbach torrent was permitted and confirmed with the local law, environmental law and forest law permissions. Both the aims of the project as well as the extent of the investigation area result from balancing and weighting of all relevant interests under the constraints of the available financial resources.

\subsection{Intention of experimental and numerical modelling}

The main objective for both the experimental and numerical modelling is to find a suitable design for the closing-off structure that entirely fulfills the aforementioned aspects 15. For this purpose, a preliminary study applying a hydrodynamic 3-D numerical model is firstly accomplished. It is set up at the prototype scale by using the FLOW-3D software (Flow Science Inc., 2012) and exclusively simulates the hydrodynamic processes under steady discharge conditions. With the assumptions of a fixed and uniform bed level in the deposition basin and the absence of any accumulation processes near the bridge and in the paved channel, different design layouts of the closing-off structure are evaluated pertaining to its effects on the hydraulics in the near range of the bridge. The simulations are accomplished for different flow conditions from low to flood flow. Accordingly, a preselection of the most suitable design layouts is obtained with the numerical model before testing them in the experimental model. The latter is accomplished with particular respect to the bed-load transport processes. In the physical scale model, design flood conditions are considered in terms of a simplified quasi-unsteady operation mode (Fig. 2b).

\section{Hydrodynamic numerical model - preliminary study}

\subsection{Model set up}

The numerical model contains the entire deposition basin, except for a small area upstream at the outlet of the canyon. It extends to the paved channel about $50 \mathrm{~m}$ downstream of the overflow section (Fig. 1a). Within the FLOW3D software (Flow Science Inc., 2012) terrain and builtin/protection structures are spatially discretised with a structured orthogonal mesh consisting of 4 mesh blocks (mb) (Fig. 3). mb 1 features a comparatively coarse resolution of $0.5 \mathrm{~m} \times 0.5 \mathrm{~m} \times 0.25 \mathrm{~m}$, since this area of the basin is merely relevant for providing adequate inflow conditions, but circumstantial for the flow analysis at the basin's outlet. The remaining model area is represented with double grid resolution.

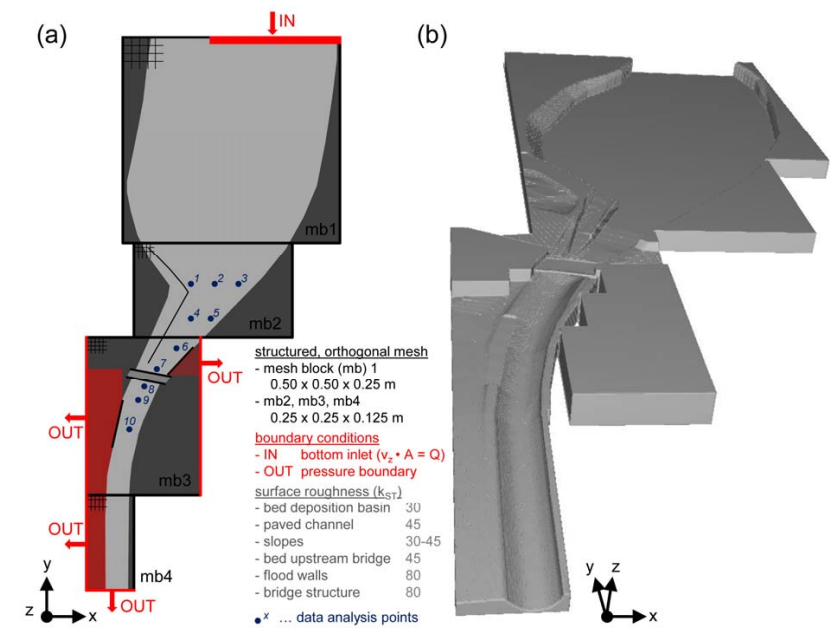

Fig. 3. (a) Scheme of the 3-D numerical model set up with the FLOW-3D software; (b) preview of the discretised geometry (FAVOR-model).

The input boundary is defined as a bottom inlet, which is represented by a small and accurately defined area at the upstream model boundary and inflow velocities in a vertical direction. At the outlets, pressure boundary conditions are specified, each with the assumption that unrealistic backwater effects are avoided. These outflow boundary conditions are set up at the downstream edge of the paved channel (mb 4), along the flood plain on the orographic right-hand side of the paved channel ( $\mathrm{mb} \mathrm{3}, \mathrm{mb} 4)$, as well as on the orographic left-hand side in the near range of the bridge (mb 3). The latter is for the case of overtopping of the flood walls in the critical range upstream of the bridge (Fig. 3). The light grey shaded area in the model scheme represents the active flow area. The remaining parts of the grid are blocked with solids in order to considerably reduce the total number of active cells from 5.02 mil. to 1.96 mil. and thus the computation time.

Concerning the turbulence options in the numerical simulations, the standard two-equation $(\mathrm{k}-\epsilon)$ turbulence model is set.

Measurement data, as for example a stage-discharge relation at a certain spot in the paved channel, is not available for model calibration. Experiences on impacts and consequences of historic flood events are, however well reputed. They characterize the aggradation processes within and beyond the channel and the spots of lateral overtopping. This information is mainly relevant for the validation of the experimental model but not applicable for the numerical model. Accordingly, surface roughness parameters in the numerical model are specified with typical guide values found in literature and the focus is put on the relative comparison between the different layouts of the closing-off structure and the present situation, respectively. Besides, a proper calibration of the numerical model without considering bed-load transport processes 
is not practical. In Fig. 3 the chosen roughness coefficients are displayed as Strickler coefficients $\mathrm{k}_{\mathrm{ST}}$ (Strickler, 1923). They amount to $30 \mathrm{~m}^{1 / 3} \mathrm{~s}^{-1}$ in the bed of the basin, to 30 $45 \mathrm{~m}^{1 / 3} \mathrm{~s}^{-1}$ at the slopes and to $45 \mathrm{~m}^{1 / 3} \mathrm{~s}^{-1}$ along the channel section situated upstream of the bridge and the paved channel. The value $80 \mathrm{~m}^{1 / 3} \mathrm{~s}^{-1}$ is chosen to be representative of smooth concrete surfaces, as well as for the flood walls and the bridge structure.

The numerical analysis contains the simulation of low flow and flood discharges within the range of $10-55 \mathrm{~m}^{3} \mathrm{~s}^{-1}$. By starting with a specific initial state condition, the computation times of the simulations are set in a way that steady state flow conditions are achieved. The assessment of the steady state condition and the simulation results mainly focusses on the range covered by the mesh blocks mb 2 and mb 3 (Fig. 3). Ten "data analysis points" are defined within this section. This way the output of specific flow parameters, such as nearbottom flow velocities or Froude numbers at these spots is accomplished. These parameters are also used for the assessment of the steady state condition.

\subsection{Closing-off structure design layouts}

Figure 4 illustrates design layouts of the basin's closingoff structure, which are analysed with the numerical model. They are collated with the present situation, not containing any structure upstream of the bridge cross section.

The layout "plan" represents the first draft devised by the Austrian Service for Torrent and Avalanche Control (WLV, 2011). Aiming for an increase in discharge-specific bed shear stresses between the structure and the bridge due to a certain flow acceleration effect, the structure is formed as a sinusoidal concrete sill with a height of $1.5 \mathrm{~m}$ and a centrally arranged opening. The overall height of the structure results in a significant increase of the bed-load deposition capacity to about $28000 \mathrm{~m}^{3}$, when assuming an aggradational grade of $5 \%$ in the basin. The structure is situated about $40 \mathrm{~m}$ upstream of the bridge. The centrally arranged opening allows for the operation with excavators to enforce the transport of sediment during extreme flood events with intensive sediment loads.

Layout "opt 1" contains a concrete sill, featuring an identical height and location of its upper edge as for "plan" and the same opening dimensions. However, the downstream face is formed straight-lined and ranges to the upstream edge of the bridge. Providing that the sinusoidal shape of layout "plan" results in a disadvantageous hydraulic jump, or its spatial range of influence is confined to a small area, the shape of "opt 1" satisfies these aspects. Layout "opt 2" corresponds to option "opt 1"; it only differs from "opt 1 " as the opening is located on the left-hand side of the channel.

Design layout "opt 3"s sole distinction lies in an increase of the channel gradient to about $4 \%$. It provides a smooth change in the gradient, starting with the aggradation slope of $5 \%$ in the basin, reducing it to $4 \%$ upstream of the bridge

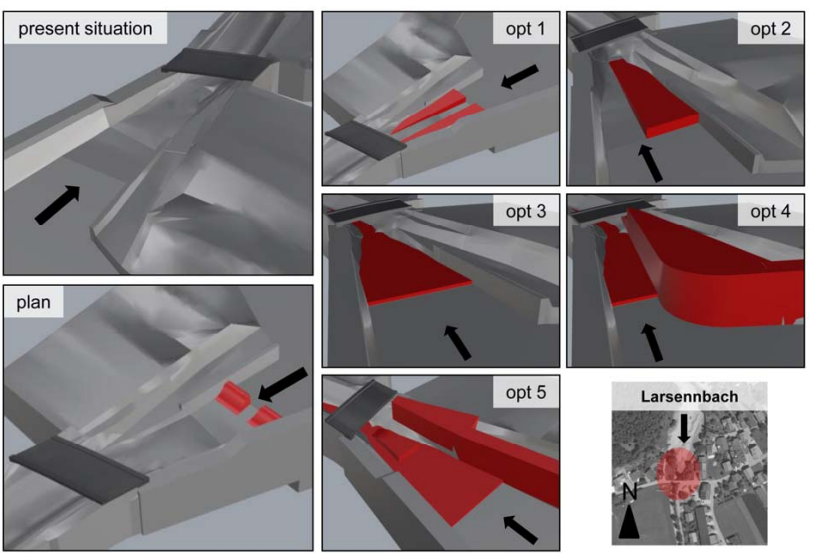

Fig. 4. Situation at the outlet of the deposition basin - present situation and design layouts of the closing-off structure.

and finally decreasing it to $3 \%$ in the paved channel. With the avoidance of any abrupt changes of the gradient and its general increase at the bridge, higher bed-load transport rates may be achieved there. The associated bed sill at the upstream edge of the structure features a height of $0.4 \mathrm{~m}$; it is situated in accordance with the other options.

Layout "opt 4" is a combination of both the increased channel gradient, just as in "opt 3", and a contraction of the channel. Even though this results in a noticeable reduction of the available cross section, the water levels during flood discharges are intended to decrease due to higher flow velocities and lower bed-load accumulation. Further, a naturally regulated input of material from the basin into the contracted channel section is expected. Design layout "opt 5" is principally derived from first draft "plan". In contrast, the structure is located right before the bridge-overpassed profile, with openings on both sides rather than in the centre.

\subsection{Results}

Referring to the aforementioned design options (Fig. 4), the results from hydrodynamic numerical modelling are highlighted in Figs. 5 and 6. Every layout was tested on the (steady state) discharges $Q=10 \mathrm{~m}^{3} \mathrm{~s}^{-1}, Q=30 \mathrm{~m}^{3} \mathrm{~s}^{-1}$ and $Q=55 \mathrm{~m}^{3} \mathrm{~s}^{-1}$. The latter is equivalent to the $\mathrm{HQ}_{150}$-design flood peak, when the bed-load component - assumed to be $10 \%$ of the clear water fraction (WLV, 2011) - is considered as an admission flow to the clear water hydrograph (Fig. 2b).

Figure 5 illustrates the flow velocity vector norms $\mathrm{v}_{25}$, captured at the spots of the ten data points (Fig. 3) $0.25 \mathrm{~m}$ above the channel bed. The distance of $0.25 \mathrm{~m}$ to the channel bed is chosen in order to be located within the nearbottom layer of transported sediment and as well outside of the boundary cell at the transition to the channel bed. The diagrams in the top row of Fig. 5 contain the absolute values of $\mathrm{v}_{25}$. The relative difference to the present situation, commonly described by the ratio $\frac{\left(v_{25, \text { designlayout }}-v_{25} \text {,actualcondition }\right) \cdot 100}{v_{25} \text {,actualcondition }}$, 
is illustrated for every design layout in the subjacent diagrams. The bars in the diagrams represent the results for $Q=55 \mathrm{~m}^{3} \mathrm{~s}^{-1}$. Coloured marks denote to the values for the conditions with $Q=30 \mathrm{~m}^{3} \mathrm{~s}^{-1}$ (blue) and $Q=10 \mathrm{~m}^{3} \mathrm{~s}^{-1}$ (red).

Figure 6 shows a set of perspective views, each displaying the steady state flow situation in the near range of the bridge for a specific simulation run. The flow field contours represent the Froude numbers, which are calculated on the basis of depth averaged flow velocities and the corresponding water depths. The stereolitography model of the bridge structure is displayed for the present situation only. Of course, it was considered in all simulation runs in order to adequately simulate possible damming effects caused by the bridge deck.

Firstly focusing on the results for the present situation, a rather uniform flow field is evident for both low and high discharges. The present bypass section upstream of the bridge is activated at about $Q=30 \mathrm{~m}^{3} \mathrm{~s}^{-1}$; lateral overtopping on the right-hand side downstream of the bridge only occurs at $Q=55 \mathrm{~m}^{3} \mathrm{~s}^{-1}$. Insignificant overtopping on the left-hand side upstream of the bridge further arises, yet the water level does not reach the bridge deck level. Both the near-bottom velocities and the Froude number plots reveal a considerable increase in discharge-specific bed shear stresses between data points 6 and 8 (Fig. 3): for $Q=55 \mathrm{~m}^{3} \mathrm{~s}^{-1}$ the velocities increase from about $0.6 \mathrm{~m} \mathrm{~s}^{-1}$ at the data points $1-3$ to $1.5 \mathrm{~m} \mathrm{~s}^{-1}$ at data point 6 , to $3.6 \mathrm{~m} \mathrm{~s}^{-1}$ at data point 8 and finally to about $4.5 \mathrm{~m} \mathrm{~s}^{-1}$ downstream of the bridge at the data points 9 and 10. For the lower discharges the values are marginally less. The Froude numbers depict a smooth change from sub- to supercritical flow regime in general. However, a notable raise appears right below the bridge structure.

Aiming for an increase in shear stresses directly upstream of the bridge (in the channel section between data points 4 and 8), so as to force bed-load transport and to avoid the bulk of bed-load aggradation, the "plan", "opt 1", "opt 2", "opt 3 " and "opt 5" design layouts do not perform better than the present situation: the velocities $\mathrm{v}_{25}$ at the data points are similar to those of the reference situation, except for a few selective spots alongside the outlet structures. As can be seen for instance in design option "plan", the velocities at data point 6 are considerably higher for both the low and medium discharge. Data point 6 is placed directly downstream of the centrally arranged opening. In the case of $Q=10 \mathrm{~m}^{3} \mathrm{~s}^{-1}$, the sinusoidal concrete sill is only insignificantly overflowed. Thus, the flow entirely passes through the opening and features higher velocities and Froude numbers. With an increase in flow overtopping the concrete sill, the impact of the opening on the flow field characteristics decreases. The situation for the "opt 1" and "opt 2" layouts is similar in each case: as long as the structure is not entirely overflowed, the flow is controlled and canalised by the outlet structure. Once the discharge further increases, this effect disappears. Summarising the effects of the responded design layouts, an increase of bed-load transport rates is not expected for the entire flow spectrum, especially not for the design event. Moreover, the structural measures cause turbulences and in some cases for specific discharges a hydraulic jump, which is a disturbing factor for a continuous sediment transport process. The characteristics of lateral overtopping on the left-hand side at the bridge and downstream on the right-hand side are similar as in the reference situation.

A distinct modification of the flow conditions and the velocities $\mathrm{v}_{25}$ in particular results for design layout "opt 4": for the entire flow spectrum, the $v_{25}$ values are comparatively lower at the data points 1-3 (relative differences between $-70 \%$ and $-16 \%$ ), but distinctively higher at the data points 5-10 (relative differences up to $+237 \%$ ). At the data points $6-10$, the velocities are all roughly the same and are consistent with the conditions in the paved channel $\left(3.75 \mathrm{~m} \mathrm{~s}^{-1}\right.$ $5.55 \mathrm{~m} \mathrm{~s}^{-1}$ ). Accordingly, the effects of layout option "opt 4 " are a slight damming at the end of the deposition basin upstream of the outlet structure and a uniform and consistently supercritical flow alongside the structure towards the transition into the paved channel. This being said, "opt 4" is an auspicious layout option in order to largely minimize the aggradation processes. Besides, the simulation run with $Q=55 \mathrm{~m}^{3} \mathrm{~s}^{-1}$ delivers marginally lower amounts of water passing the overtopping section and, most notably, no overtopping on the left-hand side upstream of the bridge (Fig. 6).

On the basis of the results from hydrodynamic numerical modelling, the primary focus within the morphodynamic experimental model is put on the present situation and the "opt 3 " and "opt 4" design layouts.

\section{Morphodynamic experimental model (1:30)}

\subsection{Model set up}

The physical scale model covers the same area as the numerical model (Fig. 2a). Using Froude's similarity law (Strobl and Zunic, 2006) the model scale is chosen to be $1: 30$. Channel sections, slopes, flood walls and the bridge structure represent immobile structures within the model construction. They are built with epoxy resin and fibre glass, rigid PVC, foamed polystyrene elements and formwork panels. Each element is patterned with a surface roughness corresponding to the prototype conditions.

In the area of bed-load deposition, a mobile bed layer is placed. The gradient amounts to $5 \%$ and complies with the expected aggradation slope in the basin. Its sediment characteristics correspond to those of the material which is dynamically supplied at the upstream boundary: referring to the prototype scale, the mean grain size $d_{\mathrm{m}}$ is $9.8 \mathrm{~cm}$, the $d_{90}$ amounts to $28.6 \mathrm{~cm}$. The coefficient $\left(d_{90} / d_{30}\right)$, indicating the degree of uniformity, is 7.3. The sediment inventory well fits the typical conditions of Limestone Alps torrents and conforms, for example, to the analysis done by Schroll (2012) at the Salzbergbach, a torrent catchment which is also situated 


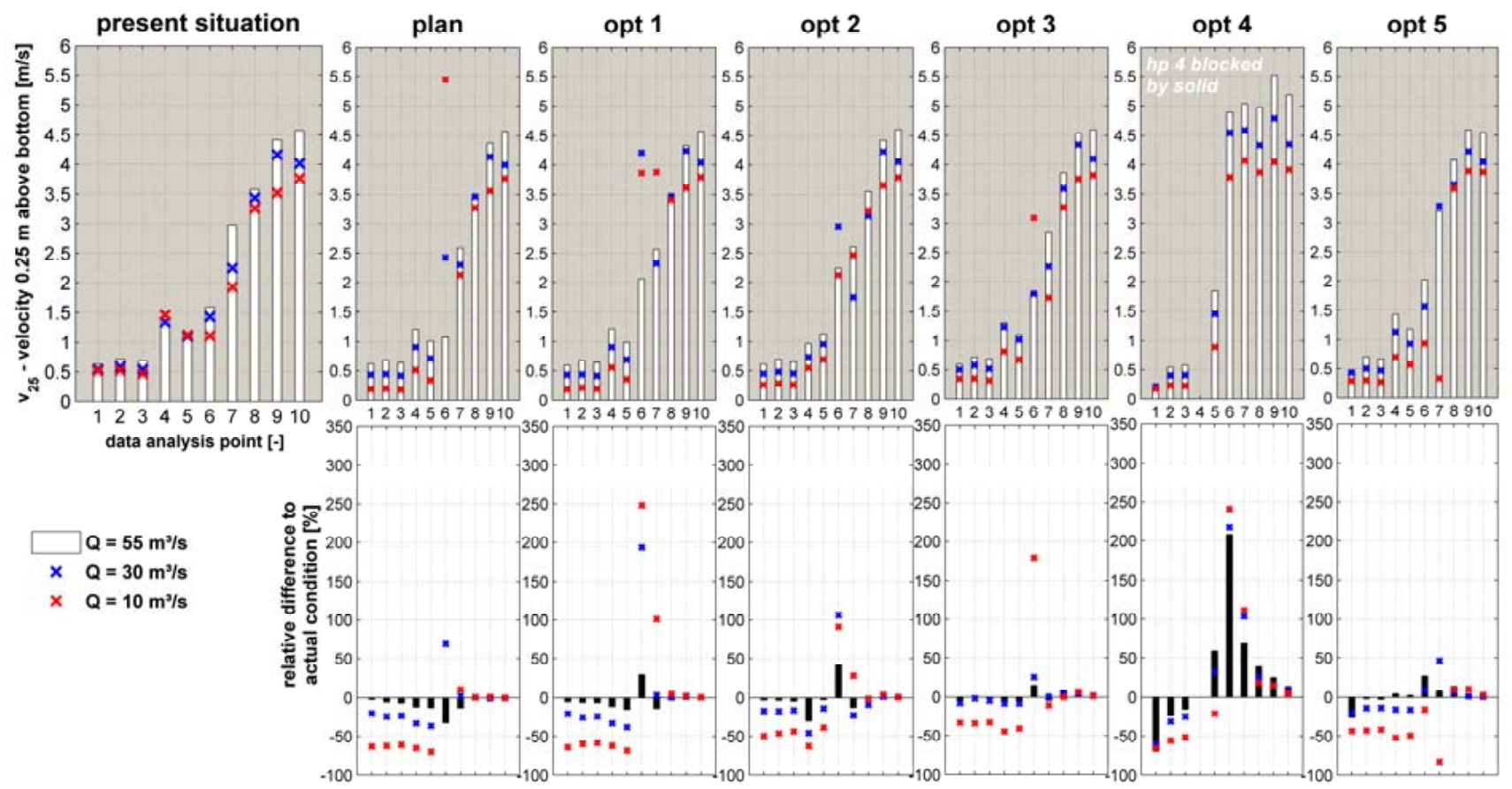

Fig. 5. Results from hydrodynamic numerical modelling for the discharges $Q=10 \mathrm{~m}^{3} \mathrm{~s}^{-1}, Q=30 \mathrm{~m}^{3} \mathrm{~s}^{-1}$ and $Q=55 \mathrm{~m}^{3} \mathrm{~s}-1-$ top row: near-bottom velocities $v_{25}$ at the data analysis points 1-10 (Fig. 3) for the present situation and the design layouts (Fig. 4); bottom row: relative differences $\frac{\left(v_{25} \text {, designlayout }-v_{25} \text {,actualcondition }\right) \cdot 100}{v_{25} \text {,actualcondition }}$ of $v_{25}$, each percental with relation to the present situation.

in the Tyrolean Northern Limestone Alps. The specification of the sediment characteristics is based on samples from two neighbouring torrents, which have been analysed by RudolfMiklau et al. (2006) after the disastrous extreme flood event in August 2005 (Schnanner Bach and Starkenbach catchments). This data greatly represents sediment, which is expected to be relevant for flood discharge conditions. The process nature of these torrents corresponds to Larsennbach's. Further, the 2005 flood featured hydrological characteristics which are also typical for the Larsennbach catchment (Sect. 2.1). Within a field survey for this study, soil samples were also taken (procedure according to Fehr, 1987) at specific spots in the deposition basin. Depending on the position of the spot in the basin, the grain size is up to one order of magnitude smaller than those mentioned before. The samples were collected in December, shortly after a large part of the material deposited during previous events was excavated. Thus, they are considered to be not fully representative for transported sediment during flood discharge conditions. However, the sampled characteristics were initially tested within experimental modelling before modifying the sediment mixture according to samples of the two neighbouring torrent catchments, which had been taken right after a major flood event. From a qualitative viewpoint, these initial tests showed an aggradation and transport process behaviour in the deposition basin and in the lined trench, which did not conform to experiences of well reputed historic flood events.
Using the material according to the analysis in the neighbouring torrents after the 2005 flood event, the accomplished tests met the reported prototype process characteristics well. The experimental modelling was as well examined from the Austrian Service for Torrent and Avalanche Control as from involved residents.

For the experimental test series, quartz sand is used in a mixture that correlates with the prototype characteristics. The minimum grain size in the model is chosen to be $0.5 \mathrm{~mm}$. The limit of $0.5 \mathrm{~mm}$ or rather $1.5 \mathrm{~cm}$ in prototype scale is set in a manner that all the sediment smaller than this value is added to the next larger bed-load fraction $(0.5$ to $1.0 \mathrm{~mm}$ or rather 1.5 to $3.0 \mathrm{~cm}$ in prototype scale).With this configuration and at a model scale of $1: 30$, any influential scale effects are precluded by consideration of the flow conditions in the section upstream of the bridge and in the paved channel. The grain-related Reynolds numbers consistently exceed the critical range of 60-80, as for example specified by Aufleger (2006). Further, with regard to the transport capacities in the experimental model, the model set up can be considered to be on the safe side, as the finest sediment fraction is modelled marginally larger than in prototype conditions.

Figure $2 \mathrm{~b}$ illustrates the $150 \mathrm{yr}$ design flood hydrograph for the Larsennbach torrent. It was defined by the Austrian Service for Torrent and Avalanche Control (WLV, 2011) and computed with the ZEMOKOST rainfall-runoff model (Kohl, 2011). Within rainfall-runoff modelling, intensity, 


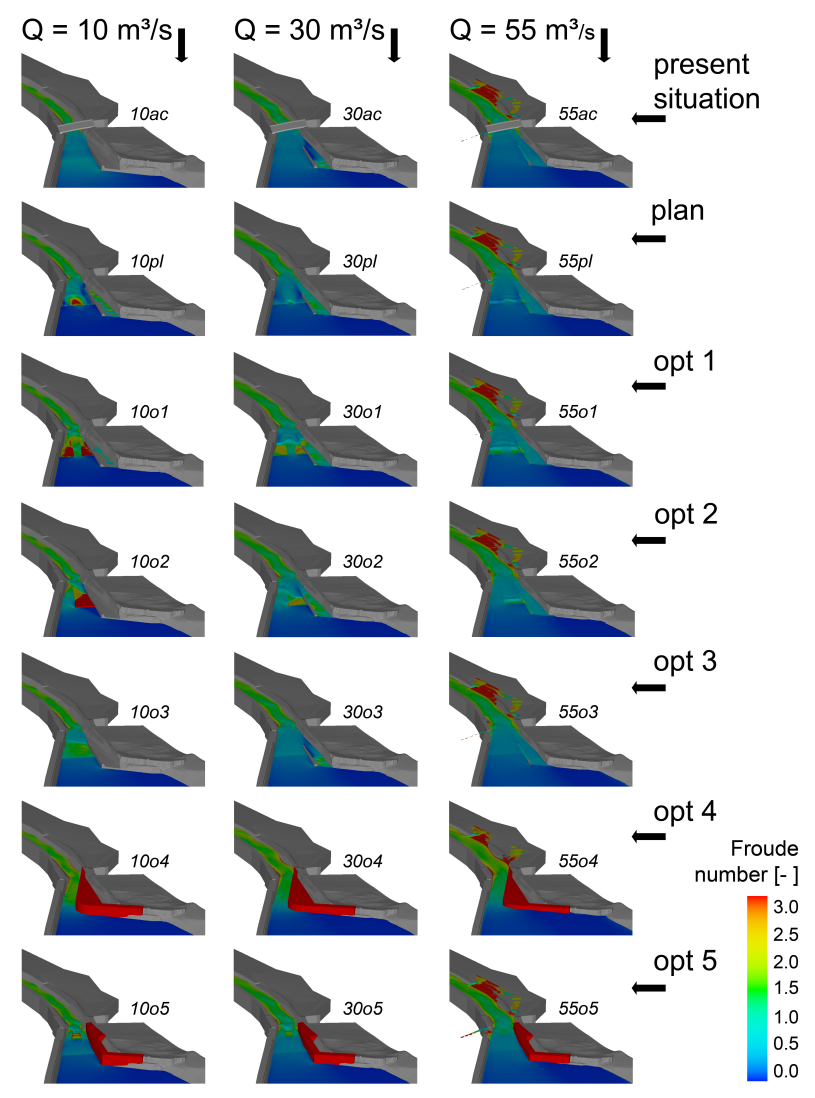

Fig. 6. Results from hydrodynamic numerical modelling for the discharges $Q=10 \mathrm{~m}^{3} \mathrm{~s}^{-1}, Q=30 \mathrm{~m}^{3} \mathrm{~s}^{-1}$ and $Q=55 \mathrm{~m}^{3} \mathrm{~s}^{-1}-$ (steady state) flow conditions and Froude numbers, based on depthaveraged flow velocities, for the present situation and the design layouts (Fig. 4); the geometry within the images is displayed with each of the stereolitography models.

duration and temporal pattern of the triggering rainfall were varied. Featuring a reoccurrence interval of $150 \mathrm{yr}$ each, these rainfall events result in flood hydrographs at the catchment outlet with different peak discharges and total volumes. Due to the relevance and the impact of the bed-load transport processes on the flood risk at the Larsennbach torrent, not the hydrograph with the highest peak but that with the highest total discharge load is selected as the decisive and most unfavourable scenario. It yields the largest amount of incoming bed load and ensures a continuous input of sediment in the deposition basin during the falling limb of the hydrograph. This process behaviour has been documented by residents during the past historic flood events and is therefore evaluated to be crucial for the appearance of heavy aggradation in the lined trench and for overbank sedimentation. The red line in the diagram represents a quasi-unsteady simplification of the discharge hydrograph which features the same total discharge as the ZEMOKOST hydrograph. This graph is used as an input for all experimental test runs. For practical rea- sons and due to the insignificance of very low discharges in the end of the design flood, each test run is stopped after the duration of $70 \mathrm{~min}$, meaning $6 \mathrm{~h} 23 \mathrm{~min}$ in the prototype scale (grey shaded area in the diagram in Fig. 2b).

Due to the topographic shape of the deposition basin, the flow path through the basin is rather changeable and does not cover its entire width; depending on the bed layer's current topography and the bed-load supply from upstream, the flow either follows the embankment base on the left- or right-hand side. This process has been repeatedly documented in the field by local residents and the Austrian Service for Torrent and Avalanche Control. In order to satisfy this in the experimental analysis, the design layouts are tested with two different flow path specifications in the basin. For it, the flow is initially disposed in the appropriate direction at the upstream boundary range. At first, the design layouts are tested without any input of bed load from upstream, meaning that the assembled bed layer in the basin is flushed. Design layouts that show good results are additionally tested with sediment supply from upstream to check for the effect of a large and sufficiently lasting sediment influx. The input rates amount to approximately $5 \%$ of the isochronical appearing discharge. This is primarily done for those design layouts, which already delivered good results in the hydrodynamic numerical model. The difference of the modelled sediment input rates and the bed-load fraction of roughly $10 \%$ under design flood conditions has a purely practical reason within experimental modelling: The input of material in the physical scale model was done manually. Thereby, $5 \%$ means the maximum fraction, where the allocation and the constant input into the model over the duration of 70 min could be reasonably managed. Besides, qualitative tests with higher input rates delivered that the additive material is immediately deposited at the input location in the upper part of the basin and does not affect the situation at the deposition basin's outlet.

All scale model tests are logged with photos and videos. Erosion and aggradation processes are analysed with laserscan measurements.

\subsection{Results}

Figure 7 contains snapshots from the experimental scale model tests for the "opt 3" and "opt 4" design layouts. In both cases, the deposition basin was previously filled with sediment in order to reproduce an aggradation slope of $5 \%$ as an initial state in the basin. Additional sediment was supplied at the upstream boundary. Relating to the quasi-unsteady flood hydrograph (Fig. 2b), the input rates amounted to about $5 \%$ of the discharge. In both cases, the bed-load input was placed at the upstream boundary in a way that the flow path in the basin developed on the left-hand side. The snap shots illustrate the conditions in the near range of the bridge at the times of the peak discharge $\left(Q=49.8 \mathrm{~m}^{3} \mathrm{~s}^{-1}\right)$, during the falling limb of the hydrograph $\left(Q=28.5 \mathrm{~m}^{3} \mathrm{~s}^{-1}\right)$ and at the end of the test runs. 


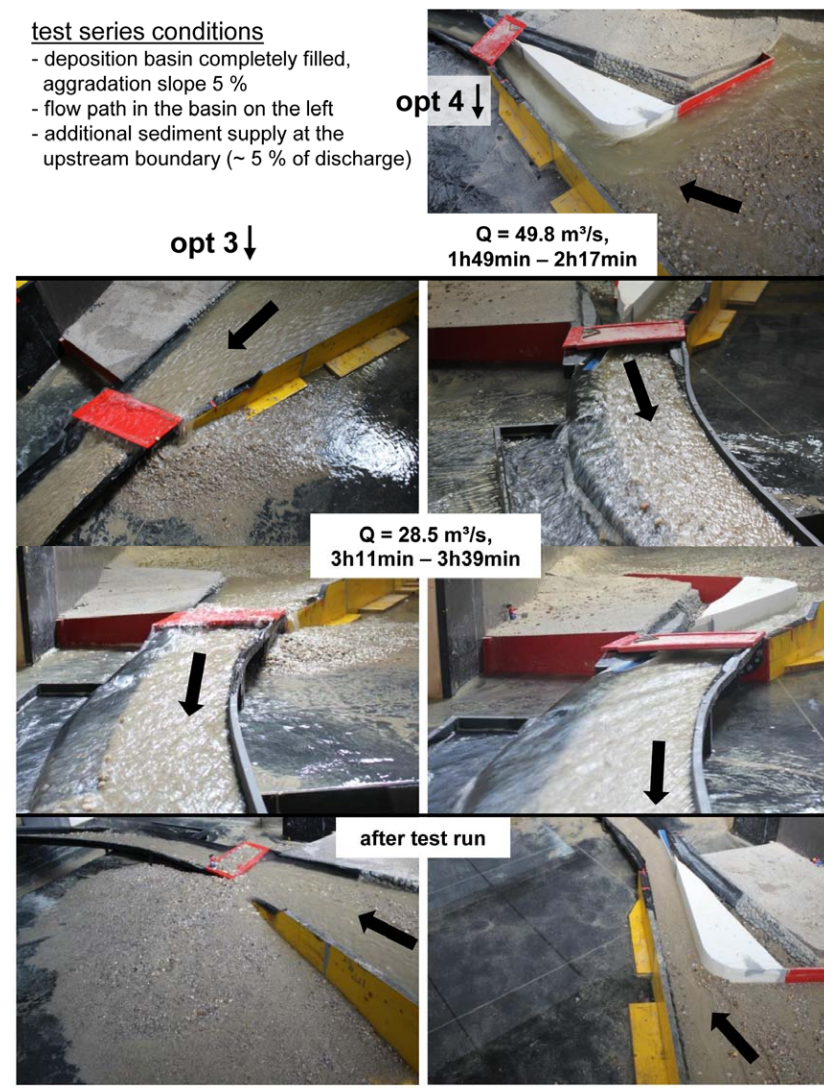

Fig. 7. Results from experimental modelling for the "opt 3" and "opt 4" design layouts (Fig. 4) - situation in the near range of the bridge during and at the end of the flood hydrograph (Fig. 2).

For design layout "opt 3" the flood-related processes could be observed with the experimental model as follows: over the entire period of the flood wave the bed shear stresses were too low in order to rudimentarily prevent aggradation in the near range of the bridge. Accumulation already appeared during the rising limb of the flood wave. Due to the continuous supply of sediment in the basin and from the upstream boundary the bed level alongside the outlet structure constantly rose, associated with a reduction of the clear height below the bridge. After about three hours of simulation (prototype scale) - during the falling limb of the flood wave, as the discharge considerably decreased again but the sediment entry still was substantial - the bed level reached the bridge deck. Overbank sedimentation occurred on the left-hand side upstream of the bridge. The discharge in the paved channel below the bridge diminished considerably. At the end of the test run, a massive accumulation of sediment in the settlement area on the left-hand side of the channel was observed. Along the paved channel, significant accumulation appeared as well. The amount of sediment passing by the overtopping section on the right-hand side of the paved channel, however, was small (Fig. 7).
Comparing this experimental test run with the one for "opt 3", but without any further sediment supply at the upstream boundary (Sect. 4.1), a significant difference of the amounts of accumulation in the channel becomes apparent. With the absence of any supply from upstream, the sediment initially placed in the basin was flushed out (along the flow path in the basin) within a time frame of about $2 \mathrm{~h} 45 \mathrm{~min}$. Subsequently, a lot less sediment entered the outlet section during the falling limb of the hydrograph, causing less accumulation and, above all, no overtopping of sediment into the settlement area. The test run without extra sediment supply at the upstream model boundary proved to be not representative of the natural conditions at the Larsennbach torrent, even though it means a less labour-intensive test run and primary allows for a qualitative assessment of the design layout. The observed effect of a continuous sediment supply from upstream points out those process/catchment characteristics at the Larsennbach torrent involving a particular hazard potential for the adjacent populated area; namely the unlimited amount of sediment, which is potentially available for remobilization in the catchment under the influence of mean and high flow conditions.

In accordance to the results from numerical modelling, the results for design layout "opt 3 " highly correspond to those of the experimental test runs for the present situation, meaning that solely an increase of the channel gradient upstream of the bridge (Fig. 4) could not come near the aforementioned requirements of the outlet structure (Sect. 2.2).

The results from the experimental analysis with "opt 4" paint an entirely different picture (Fig. 7): due to the limitation of the channel width in combination with the channel gradient of $4 \%$ upstream of the bridge, aggradation in the near range of the bridge is largely avoided. Consequently, lateral overtopping of both clear water and sediment on the lefthand side at the bridge does not occur. The bridge structure is not endangered of clogging. Design layout "opt 4" affects the bed-load transport in the functioning of a control section: the structure causes a minor damming at the end of the deposition basin, which results in a lower but constantly controlled sediment entry into the outlet section. By providing higher bed shear stresses alongside the outlet structure - mainly due to the decrease of the channel width - the channel copes with these transport rates during the entire flood hydrograph. The bridge cross section is not blocked during the falling limb of the flood hydrograph and sediment transport along the paved channel into the receiving water course is maintained permanently. Consequently, more material reaches the Inn River than in the present situation. As stated in Fig. 8, the ratio of the total amounts of bed load leading into the receiving water course for "opt 4 " and "opt 3" is 1.33 , meaning that for the "opt 4" case the output is $33 \%$ larger. Similarly, the amount of sediment overtopping on the right-hand side downstream of the bridge is $26 \%$ larger in "opt 4 ". 


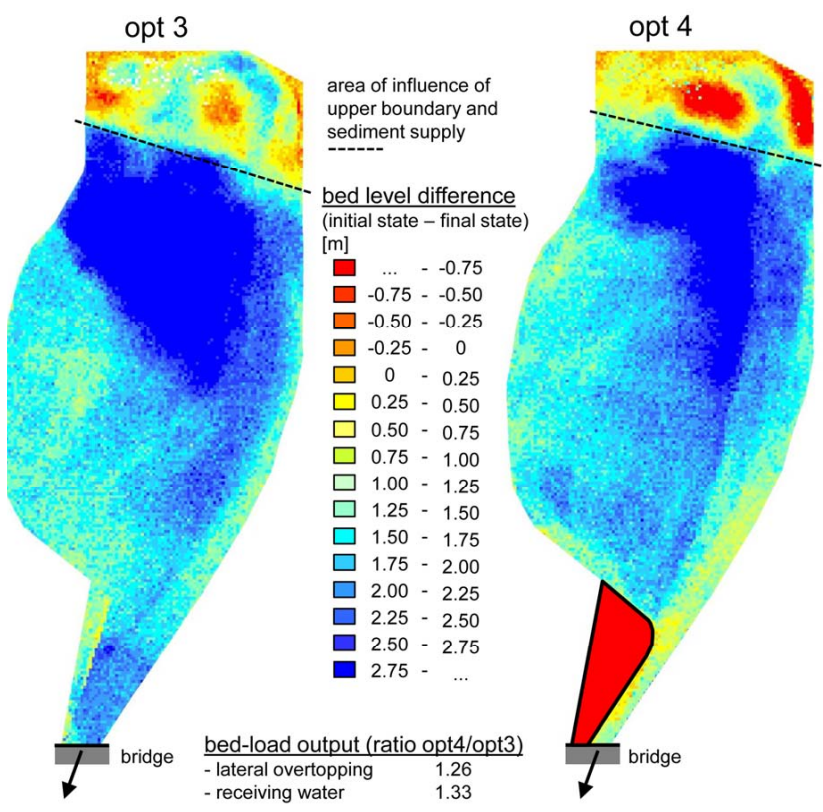

Fig. 8. Results from experimental modelling for the "opt 3" and "opt 4" design layouts (Fig. 4) - bed level changes in the deposition basin and relations of bed-load output both as lateral overtopping and entry into the receiving water course.

For the channel section along the outlet structure, at the bridge cross section and in the paved channel as well, the results from experimental modelling greatly confirm the findings from the hydrodynamic numerical model: design layout "opt 4" proved to be the most effective structure in order to prevent overtopping into the settlement area, to continuously maintain bed-load transport in the channel, to maximise the entry of material into the Inn River and to shift the location of overtopping from a spot with tremendous potential loss down to an area explicitly declared as space for retention in case of floods. Furthermore, the implementation of option "opt 4" optimises the use of the existing retention volume in the basin as illustrated in Fig. 8. The raster plots represent bed level differences between the final states at the end and the initial states before each the test run, surveyed by a laser scanner. Due to the marginal damming in the lower end of the basin in "opt 4", sediment is not deposited along the flow path only, but spreads over the entire width of the basin.

\section{Discussion}

\subsection{Obtained results - suggested design of the closing-off structure}

The results of numerical and experimental modelling reveal three main aspects required for a well-functioning and effective layout of the closing-off structure: the structure has to concentrate the flow within a narrower channel section up- stream of the bridge in order to ideally correspond to the flow conditions in the paved channel. The channel gradient has to be as uniform and continuous as possible from the aggradation slope in the basin to the gradient of the paved channel. Furthermore, the structure must not represent the shape of a barrier for the hydraulics that obstructs channel flow as well as sediment transport and causes additional turbulences. Design layout "opt 4" (Fig. 4) delivers on these aspects and further fulfills the aforementioned requirements of an efficient layout (Sect. 2.2): (1) the prevention of lateral overtopping into the settlement area, (2) the increase of the bed-load output from the basin and the entry into the receiving water course, (3) overbank sedimentation along the overflow section only, (4) the increase of the basin's maximum capacity due to a marginal damming effect and the optimised use of the basin's front part, (5) the possibility for excavators to assist in bed-load transport during floods and the avoidance of a pondage effect at low flow conditions.

Due to the reduction of cross-sectional area, the design option is prima facie counterproductive. However, it delivers higher velocities and accordingly lower water levels within the hydrodynamic clear water simulations and far less bedload accumulation as the present situation within experimental modelling as well.

For the constructive implementation of design layout "opt 4" the following information is relevant in addition to the fact that it is absolutely necessary to establish the structure high enough for not being overflowed: during the experimental test series with "opt 4", scouring appeared alongside the part of the wall structure, which is located in the widened area in the basin - even if only to a small extent and along a narrow strip. Within the scale model, the mobile bed layer in the basin borders directly onto the wall structure, thus, any measures for bed protection are not considered. Particular attention should be paid to this issue in the implementation. Furthermore, the wall structure's surface and the channel bed upstream of the bridge must be as smooth as possible in order to keep the drag forces low.

Regarding the impact of the optimised design layout on the sediment continuity and on the ecological conditions at the Larsennbach torrent, the bed-load transport processes are characterised by a continuously, to some extent dosed output from the deposition basin. For small discharges in the Larsennbach torrent, the outlet structure does not affect the bed-load transport, whereas for medium and flood discharges, the sediment transport processes perform more uniform than for the actual condition. The main receiving water course is assessed to feature sufficiently high transport capacities in order to fully move on the entrained material. With this in mind, also the situation for the sediment continuity is more likely improved with the optimised structure at the end of the deposition basin. With regard to the passability of the analysed section of the Larsennbach torrent, the optimised design layout of the outlet structure does not seem to represent a barrier. Consequently, without explicitly focusing also 
on the ecological aspects of the planned protection measures in the planning process and the definition of the project aims, the optimised torrent defence measures basically conform to the ecological requirements.

\subsection{Applied methods/models}

Reflecting the methods/models used within this study for the optimisation of a deposition basin's outlet structure, the conclusions are stated as follows: the use of a numerical model is meant to enhance, but by no means replace a physical scale model analysis in this task. Adequate numerical modelling of bed-load transport processes, featuring very high solid concentrations in the runoff, and focusing on small-scale processes and patterns, is subject to current and future research. Appropriate numerical models allowing for the systematic and comprehensive representation of these processes, which are in accordance with the author's view of these software advancements, are not yet fully developed and established in practical applications. Within the presented study a 3-D numerical clear water model is chosen in order to solely accompany and support the problem-solving process in the physical scale model. Certainly, the application of a process conform numerical bed-load transport model (e.g. HYDRO_GS2D, Nujic, 2009, 2012; BASEMENT, Faeh et al., 2011) or of a debris flow model (e.g. TRENT2D, Rosatti and Begnudelli, 2013) would be the natural choice. Nevertheless, a 3-D hydrodynamic model was applied for the analysis at the Larsennbach torrent, which can be accounted for with the following aspects/arguments:

1. Relevance of three dimensional hydrodynamic effects at the transition of deposition basin and lined trench; well established three dimensional morphodynamic models are not available.

2. Non-relevance of debris flow processes in the Larsennbach torrent catchment, since the torrential hazard processes correspond to the typical Limestone Alps process behaviour: satisfactory significance of the hydrodynamic model within the course of a preliminary study is given, so as to deduce conclusions from the bottom near velocity field on the character of bed-load transport processes.

3. Time expenditure for the application of a 2-D morphodynamic model as a preliminary study of the experimental test series: the morphodynamic model is characterized by considerably higher computation times than the hydrodynamic model. The benefit of a comparatively expeditious tool, which allows for a quick and manageable initial screening of design layouts within the hybrid modelling concept, is fully given.
4. Lack of calibration/verification data for the morphodynamic model: from the authors' viewpoint, the validity and thus the benefit of a morphodynamic model only appears, if there is measurement data available for model calibration and validation. Morphodynamic models usually contain a large number of parameters, which to some extent have a large impact on the results. Without the availability of any field data, the significance of a sediment transport model is not fully given.

With the application of FLOW-3D (Flow Science Inc., 2012), highly effective results and a very good first assessment of the effects of the tested design layouts is achieved within this study. They ensure an effective and well organized test programme in the hydraulic laboratory. Taking all these issues into consideration, the application of a hydrodynamic numerical model, accompanying and enhancing a morphodynamic physical scale model, proves to be a proper and advisable modelling approach for the task presented in this study. The relevance of realising a physical scale model is reflected not only by the lifelike representation of the bed-load transport processes, but also by the possibility of representing important findings to the public and authorities in order to further motivate their acceptance.

Addressing to aspects for further research, the additional application of a morphodynamic model represents an interesting and valuable task, even though it is highly elaborate. It could be calibrated with the results from experimental modelling and be used to perform further torrential hazard scenarios at a low cost or to extend the lateral and downstream model boundaries in order to better simulate overbank sedimentation and the bed-load transport processes in the receiving water course.

Referring to the chosen design flood hydrograph and the bed-load characteristics within experimental modelling, the testing of further flood hydrographs and a sensitivity analysis concerning a variation of the grain size distribution undoubtedly represent interesting tasks for further research. Thereby, additional information from the upper part of the Larsennbach catchment would be a valuable input. Changes in the characteristics of the incoming sediment during the time frame of a flood hydrograph are of basic interest, since all accomplished experimental tests were run with the supply of bed load, where the grain size distribution was set constant and independent from discharge. Further, an experimental test series could be accomplished, where the effects of an overload scenario, for example a $300 \mathrm{yr}$ flood event, on the extent of overbank sedimentation and the extent of losses is analysed. These tests could deliver highly valuable information for practical evacuation plans, the use of temporary protection measures and the quantification of residual risks. 
Acknowledgements. The presented study was assigned and significantly funded by the Austrian Service for Torrent and Avalanche Control (WLV, Imst regional headquarters), which is subordinated to the Austrian Federal Ministry of Agriculture, Forestry, Environment and Water Management. The Unit of Hydraulic Engineering at the University of Innsbruck is grateful for the chance to work on this topic.

Edited by: P. Tarolli

Reviewed by: B. Mazzorana and one anonymous referee

\section{References}

Aufleger, M.: Flussmorphologische Modelle - Grundlagen und Anwendungsgrenzen, Anwendung und Grenzen physikalischer und numerischer Modelle im Wasserbau, in: Berichte der Versuchsanstalt Obernach und des Lehrstuhls für Wasserbau und Wasserwirtschaft der Technischen Universität München, Munich, Germany, Band 104, 198-207, 2006 (in German).

Aulitzky, H.: Vorläufige, zweigeteilte Wildbachklassifikation, Wildbach- und Lawinenverbau, 48, 7-60, 1984 (in German).

Bätzing, W.: Die Alpen: Entstehung und Gefährdung einer europäischen Kulturlandschaft, Beck, C. H., Munich, 1991 (in German).

Bergmeister, K., Suda, J., Hübl, J., and Rudolf-Miklau, F.: Schutzbauwerke gegen Wildbachgefahren - Grundlagen, Entwurf und Bemessung, Beispiele, Ernst \& Sohn, Berlin, 2009 (in German).

Bezzola, G. R. and Hegg, C.: Ereignisanalyse Hochwasser 2005, Teil 1 - Prozesse, Schäden und erste Einordnung, Bundesamt für Umwelt BAFU, Swiss Federal Institute for Forest, Snow and Landscape Research WSL, Umwelt-Wissen, 0707, Bern, 2007 (in German).

DIN 19663: Wildbachverbauung - Begriffe, Planung und Bau, Deutsches Institut für Normung e.V., Berlin, 1985 (in German).

European Parliament, Council: Directive 2000/60/EC of the European Parliament and of the Council of 23 October 2000 establishing a framework for Community action in the field of water policy, 2000.

Faeh, R., Mueller, R., Rousselot, P., Vetsch, D., Volz, C., Vonwiller, L., Veprek, R., and Farshi, D.: System Manuals of BASEMENT, Version 2.1, Laboratory of Hydraulics, Glaciology and Hydrology (VAW), ETH Zürich, available at: http://www.basement. ethz.ch (last access: 14 March 2013), 2011.

Federal Ministry of Agriculture, Forestry, Environment and Water Management (BLFUW): Technische Richtlinie für die Wildbach- und Lawinenverbauung, TRL-WLV gemäß §3 Abs 1 Z 1 und Abs 2 WBFG 1985, Fassung: Juli 2006 (in German).

Fehr, R.: Einfache Bestimmung der Korngrößenverteilung von Geschiebematerial mit Hilfe der Linienzahlanalyse, Schweizer Ingenieur und Architekt, 38/87, 1104-1109, 1987 (in German).

Flow Science Inc.: FLOW-3D, v10.0, User Manual, Santa Fe, USA, 2012.

Fuchs, S., Heiss, K., and Hübl, J.: Towards an empirical vulnerability function for use in debris flow risk assessment, Nat. Hazards Earth Syst. Sci., 7, 495-506, doi:10.5194/nhess-7-4952007, 2007.
Gems, B.: Entwicklung eines integrativen Konzeptes zur Modellierung hochwasserrelevanter Prozesse und Bewertung der Wirkung von Hochwasserschutzmaßnahmen in alpinen Talschaften - Modellanwendung auf Basis einer regionalen Betrachtungsebene am Beispiel des Ötztales in den Tiroler Alpen, Ph.D. thesis, Unit of Hydraulic Engineering, University of Innsbruck, Innsbruck, 2011 (in German).

Holub, M., Suda, J., and Fuchs, S.: Mountain hazards: reducing vulnerability by adapted building design, Environ. Earth Sci., 66, 1853-1870, 2012.

Hübl, J.: Hochwässer in Wildbacheinzugsgebieten, Wiener Mitteilungen, 216, 45-58, 2009 (in German).

Hübl, J., Jugovic, J., Erlmoser, M., Steinwendter, H., Holzinger, G., and Gruber, H.: Hydraulische Modellversuche zur Optimierung des Mündungsbereiches des Schwarzbaches in die Leoganger Ache, IAN Report 43-2, Institute of Mountain Risk Engineering, University of Natural Resources and Applied Life Sciences (BOKU), Vienna, 2002.

Hübl, J., Holzinger, G., Klaus, W., and Skolaut, C.: Literaturstudium und Zusammenstellung vorhandener Ansätze zu kronenoffenen Sperren, WLS Report 50/Band 1, University of Natural Resources and Life Sciences, Vienna, 2003 (in German).

Hübl, J., Fleisch, M., Chiari, M., and Kaitna, R.: Physikalische Modellversuche zur Optimierung der Geschieberückhaltesperre am Gadriabach (Vinschgau, Südtirol), IAN Report 144, Institute of Mountain Risk Engineering, University of Natural Resources and Applied Life Sciences (BOKU), Vienna, 2012 (in German).

Hunzinger, L. and Zarn, B.: Sediment Transport and Aggradation Processes in Rigid Torrent Channels, Interpraevent 1996, Conference Proceedings, 24-28 June 1996, Garmisch-Partenkirchen, 4, 221-230, 1996.

Huttenlau, M., Stötter, J., and Stiefelmeyer, H.: Risk-based damage potential and loss estimation of extreme flooding scenarios in the Austrian Federal Province of Tyrol, Nat. Hazards Earth Syst. Sci., 10, 2451-2473, doi:10.5194/nhess-10-2451-2010, 2010.

Kaitna, R., Chiari, M., Kerschbaumer, M., Kapeller, H., ZlaticJugovic, J., Hengl, M., and Huebl, J.: Physical and numerical modelling of a bedload deposition area for an Alpine torrent, Nat. Hazards Earth Syst. Sci., 11, 1589-1597, doi:10.5194/nhess-111589-2011, 2011.

Kerschbaumer, M.: Physikalische Modellversuche zur Planung und Optimierung des Geschiebeablagerungsplatz am Vorderbergerbach, Gem. St. Stefan im Gailtal, Diploma thesis, Institute of Mountain Risk Engineering, University of Natural Resources and Applied Life Sciences (BOKU), Vienna, 2008 (in German).

Kohl, B.: Das Niederschlags-/Abflussmodell ZEMOKOST - Entwicklung eines praktikablen Modells zur Ermittlung von Hochwasserabflüssen in Wildbacheinzugsgebieten unter Einbeziehung verbesserter Felddaten, Ph.D. thesis, Faculty of Geoand Atmospheric Sciences, University of Innsbruck, Innsbruck, 2011 (in German).

Lange, D. and Bezzola, G. R.: Schwemmholz - Probleme und Lösungsansätze, Reports of the Laboratory of Hydraulics, Hydrology and Glaciology (VAW), 188, ETH Zürich, Zürich, 2006 (in German).

Luzian, R., Kohl, B., and Bauer, W.: Wildbäche und Muren Eine Wildbachkunde mit einer Übersicht von Schutzmaßnahmen der Ära Aulitzky, Forstliche Bundesversuchsanstalt, Institut für Lawinen- und Wildbachkunde, Innsbruck, 2002 (in German). 
Mazzorana, B., Levaggi, L., Keiler, M., and Fuchs, S.: Towards dynamics in flood risk assessment, Nat. Hazards Earth Syst. Sci., 12, 3571-3587, doi:10.5194/nhess-12-3571-2012, 2012.

Nujic, M.: HYDRO_AS-2D - Ein zweidimensionales Strömungsmodell für die wasserwirtschaftliche Praxis, Rosenheim, Germany, 2009 (in German).

Nujic, M.: HYDRO_GS-2D - Arbeitsblatt Stofftransport, Rosenheim, Germany, 2012.

ONR 24800: Protection works for torrent control - Terms and definition as well as classification, 2009-02-15, Austrian Standards Institute, Vienna, Austria, 2009.

Rosatti, G. and Begnudelli, L.: Two-dimensional simulation of debris flows over mobile bed: enhancing the TRENT2D model by using a well-balanced generalized roe-type solver, Comput. Fluids, 71, 171-195, 2013.

Rudolf-Miklau, F., Ellmer, A., Gruber, H., Hübl, J., Kleemayr, K., Lang, E., Markart, G., Scheuringer, E., Schmid, F., Schnetzer, I., Weber, C., and Wöhrer-Alge, M.: Hochwasser 2005 - Ereignisdokumentation, Teilbericht der Wildbach- und Lawinenverbauung, Vienna, 2006 (in German).

Rudolf-Miklau, F., Hübl, J., Schnetzer, I. (Eds.): Ereignisdokumentation 2012 - Überblick über die Wildbachereignisse in Österreich sowie Dokumentation ausgewählter Katastrophen: Lorenzerbach (Gemeinde Trieben/Steiermark) und Firschnitzbach (Virgen/Tirol), Federal Ministry of Agriculture, Forestry, Environment and Water Management, Vienna, 2012 (in German).
Schroll, L.: Grundlagenerhebung und vereinfachte, numerische Modellierung von Geschiebetransport in einem Wildbach, Bachelor thesis, Unit of Hydraulic Engineering, University of Innsbruck, Innsbruck, 2012 (in German).

Sommer, N. and Lauffer, H.: Untersuchungen über den Feststofftransport in Gebirgsbächen der Ostalpen, 14. Internationaler Talsperrenkongress, 3-7 May 1982, Rio de Janeiro, 119-138, 1982 (in German).

Strickler, A.: Beiträge zur Frage der Geschwindigkeitszahlen für Ströme, Kanäle und geschlossene Leitungen, in: Mitteilungen des Amtes für Wasserwirtschaft, Nr. 16, Eidg. Amt für Wasserwirtschaft, Bern, Switzerland, 1923 (in German).

Strobl, T. and Zunic, F.: Wasserbau, Aktuelle Grundlagen - Neue Entwicklungen, Springer- Verlag, Berlin, Heidelberg, 2006 (in German).

WLV (Austrian Service for Torrent and Avalanche Control): Larsennbach Projekt 2011 - Technischer Bericht, unpublished, 2011.

Zollinger, F.: Die Vorgänge in einem Geschiebeablagerungsplatz Ihre Morphologie und die Möglichkeiten einer Steuerung, Ph.D. thesis, Institut für Kulturtechnik, ETH Zürich, Zürich, 1983 (in German). 